\title{
Study on the Construction Path for Ecological Personality of Chinese Citizens from the Perspective of Green Development
}

\author{
Jianyun Yang \\ Shaanxi Institute of International Trade and Commerce \\ Shaanxi, China
}

\begin{abstract}
This paper studies the inherent connection between the ecological personality construction of citizens and green development. Combined with Chinese practical situations, this paper puts forward the construction path for the ecological personality of Chinese citizens from the perspective of green development from four the aspects, including system construction, construction of ecological government, cultivation of ecological personality of citizens, and creation of ecological social environment.
\end{abstract}

Keywords—green development; citizens; ecological personality

\section{INTRODUCTION}

Chinese President Xi Jinping put forward the Five Major Development Concept of "innovation, coordination, green, openness and sharing" at the Fifth Plenum of the 18th Central Committee of the Communist Party of China and regarded green development as the important way to realize the 13th Five-Year Plan and comprehensively build a moderately prosperous society. As the subject of realization of green development, construction of the ecological personality of citizens is the security for realization of green development. However, ecological personality of citizens is not spontaneously formed. Only through cultivation can ecological personality of citizens be constructed. Construction of the ecological personality of citizens from the perspective of green development is to cultivate ecological personality suitable to green development, make personality of citizens more conform to needs of green development, improve the overall quality of citizens and promote the socialist ecological civilization construction in China at the same time.

\section{A. Study on Basic Theory}

I) Scientific connotation of the green development concept: At the Fifth Plenum of the 18th Central Committee of the Communist Party of China, Chinese President Xi Jinping put forward the Five Major Development Concept of "innovation, coordination, green, openness and sharing" and regarded green development as an important concept related to the overall development of China and a basic policy of long-term development of China in a long time, which implies that the Communist Party of China further deepens its understanding of the development rule of the socialism with Chinese characteristics and will lead the Chinese people to early realize prosperity, democracy, civilization, harmony and great rejuvenation of Chinese nation. From the perspective of the connotation of green development, green development is a kind of model innovation on the basis of traditional development and is a kind of new type development model that regards environmental protection as the important pillar for realization of sustainable development under the constraint conditions of the ecological environment capacity and resource carrying capacity. Specifically, the green development includes the following key points: firstly, it is required to regard environmental resources as the internal factor of social and economic development; secondly, it is required to regard realization of the sustainable development of economy, society and environment as the objective of green development; thirdly, it is required to regard "greenization" and "ecologicalization" of process and results of economic activities as main content and route of green development.

\section{B. Theory of Ecological Personality of Citizens}

The ecological personality of citizens is the regulation on the ecological aspect of the personality of citizens and refers to the personal characteristics possessed by citizens in order to adapt to the ecological society, which reflects concept, emotion, virtue, value judgment and other individual inclinations of citizens on the ecological society, decides attitude and choices of citizens toward the ecological environment, and appears through habits and behaviors of citizens at the same time. The ecological personality of citizens includes ecological consciousness of citizens, ecological morality of citizens, ecological concept of citizens, ecological habits of citizens, ecological behaviors of citizen and other contents. The main characteristics of ecological personality of citizens are love of nature, conservation of resources, and protection of environment. 


\section{INHERENT CONNECTION BETWEEN CONSTRUCTION OF ECOlOGICAL PERSONALITY OF CITIZENS AND GREEN DEVELOPMENT}

\section{A. Inherent Connection between the Ecological Personality Construction of Citizens and the Green Development Is Decided by Sustainable Development of Human Society}

Human beings are originally independent from nature and they are an integral part of nature. Nature is the premise and basis of survival and development of human beings. However, in the process of development, human beings get rapid development of economy at the cost of sacrifice of environment, which results in more and more serious ecological crisis at present. Moreover, China is in the crucial stage of the Reform and Opening-Up and economic development and is in the ambivalent phase of maintenance of sustainable development of economy and protection of ecological balance. Only through construction of ecological personality of citizens can human beings promote the economic development on the basis of respecting the development rule of nature; only by insisting on the green development concept can the formation of the ecological personality of citizens be further promoted so as to realize sound circulation between society and nature and achieve healthy development of the society.

\section{B. The Objective of Ecological Personality of Citizens Is Consistent with That of Green Development}

Construction of ecological personality of citizens and realization of green development are for realization of China's sustainable development and the Chinese Dream. The green development refers to a kind of economic growth and social development model with the objective of efficiency, harmony and sustainability, which pursues ecological harmony and social justice during the development of economy so as to finally realize the all-round development of harmonious society. The objective of the construction of ecological personality of citizens is to make citizens possess due personality characteristics suitable to ecological society and train ecological consciousness, ecological morality, ecological habits and ecological behaviors of citizens so as to protect nature. The purpose of them is to make human society get along well with nature, achieve mutual development, promote the China's economy to realize sustainable development and early achieve great rejuvenation of Chinese nation.

\section{The Process of the Ecological Personality Construction of Citizens Is Uniform to That of Green Development}

Firstly, the construction of ecological personality of citizens is the premise of green development. Citizens are the main body to promote green development. Promote green development, advocate and appeal to carry forward ecologization of personality of citizens. Construction and creation of green development is relied on citizens who posses ecological personality. In other words, it is relied on citizens who posses green development concept and the ability to promote green development. Only through construction of ecological personality can citizens really set up green development concept in the idea, actively connect their own behaviors with the construction of ecological civilization, consciously undertake responsibilities and obligations to protect environment, also actively safeguard their own ecological rights, cultivate ecological morality, form ecological habits and promote green development.

Secondly, green development is the safeguard for construction of ecological personality of citizens. On the one hand, green development is the guarantee for people's happy life. The whole life of human beings, especially the material life, is always relied on external nature. Therefore, safeguard of people's ecological rights and interests is the indispensable material basis and premise of guarantee for abundant life and happiness of people. On the other hand, green development can promote citizens to form ecological mode of thinking and value and make citizens consciously become the liability subject to promote green development so as to make citizens possess ecological personality and improve the mental outlook of citizens. Continuous persistence and promotion of green development is the only way to make every citizen share the entire nature in all-round and abundant ways, promote citizens gain satisfaction of material goods and improvement of mental outlook so as to carry forward the ecologicalization of personality of citizens.

\section{STUdy ON CONSTRUCTION PATH OF ECOLOGICAL Personality of Chinese Citizens From the Perspective OF GREEN DEVELOPMENT}

\section{A. The Construction Content of Chinese Citizens}

From the perspective of green development, the construction content of Chinese citizens includes enhancement of ecological consciousness of citizens, reinforcement of ecological morality of citizens, improvement of ecological knowledge and ability of citizens, formation of ecological behaviors of citizens, cultivation of ecological habits of citizens and so on.

\section{B. Construction Path Choice of Ecological Personality of Chinese Citizens from the Perspective of Green Development}

1) Imperfect and implement the law system on green development in China: The Decision of the Central Committee of the Communist Party of China on Some Major Issues Concerning Comprehensively Deepening the Reform points out that the establishment of ecological civilization must establish systematic and integrated ecological civilization institutional system, implement the most strict source protection system, damage compensation system and accountability system, imperfect environmental governance and ecological restoration system, and use system to protect the environment. (1)Therefore, promotion of green development must perfect relevant law systems, such as formulating and perfecting laws and regulations relevant to protection of air, soil, water source, resource and energy resources as well as relevant compensation for damage so as to provide strong legal guarantee for green development. Furthermore, green development involves all aspects of ecological protection and social and economical development and has the characteristics of wholeness and integrity. Therefore, relevant green 
development systems must coordinate rights and interests of all departments and aspects, give overall consideration and make overall arrangement so as to make relevant systems make a real difference.

2) Under the guidance of green development idea, intensify the ecological management position of the ecological serviceorientated government, complete the supervisory mechanism for ecological responsibilities of government and build the ecological government: When organizing the sixth collective learning on vigorous promotion of ecological civilization construction of the Political Bureau of the Central Committee of the CPC in February 2014, Xi Jinping, the General Secretary of the Communist Party of China, emphasized that, "construction of the ecological civilization concerns with the people's wellbeing. The ecological environment protection is the career where pains for the moment and gains for the millennia." And the government is the representative of public power which plays the irreplaceable functions that any enterprises/ individual and social organizations can't replace on promoting construction of ecological personality of citizens and the green development. Therefore, the intensification of ecological governance position of ecological service-orientated government, the perfection of ecological responsibility supervisory mechanism of government and construction of ecological government have become the realistic issues which need to be solved immediately for construction of ecological personality of citizens, promotion of green development and construction of beautiful China.

One of the most important reasons why ecological environment suffers such austere threats is that the government, "the visible hand", has not made reasonable and effective regulation. Therefore, the government must transform its functions as soon as possible to highlight the leading and model functions of government in promoting the construction of ecological civilization and to construct the "ecological government". The first is to establish and perfect the performance and supervisory mechanisms of governmental ecological functions including legal system for local ecological environment construction, operation mechanism for government ecological functions/ supervisory mechanism for government ecological functions, ecological evaluation system for government and administrative staff and ecological accountability mechanism etc to promote the government to perform its ecological functions and further promote the green transformation of economy. Secondly, in the practice, take the green development concept as guidance to highlight the detailed functions of government on economic development such as guidance, regulation, management and service etc. When the economic development is inconsistent with green development, the later shall prevail. The economic development shall not sacrifice environment. Completely intensify the ecological management, construct ecological construction, conduct recovery and governance to ecological environment, protect and create a pleasant ecological environment. The third is to give play to the advantage of government on publicity, intensify the education of green development concept of all citizens with administrative means, conduct ecological environment publicity and popularization to accelerate the cultivation of green talents and make the green development concept aware, acknowledged, accepted and agreed by the whole society. Enhance and cultivate the consciousness of ecological responsibility of enterprises and transfer the ecological consciousness of citizens into ecological behaviors so as to promote the formation of ecological personality of citizens through the encouragement, guidance and promotion of ecological behaviors of citizen individual and non government organizations for environmental protection.

3) Accomplish the overall construction for cultivation of ecological personality of citizens and focus on the comovement of family education, school education and community education: It mainly includes: the first is the ecological personality education for family citizenship. Parents will always be the teachers of children. And the ecological civilization quality, reasonable consumption concept and green life style of parents will exert strong influence and infection on children. Therefore the parents should insist on exerting imperceptible influence on children by the good ecological personality of themselves and cultivate the formation of ecological personality of children. Firstly, parents can attend the lectures on ecological civilization of community, read manuals about environmental protection popularization and watch the news programs on ecological civilization etc to improve their ecological knowledge and skills and enhance the communication with children on this aspect; secondly, parents can guide children to participate in the family greening work to beautify the family ecological environment so as to let children experience the beauty of nature at home; thirdly, parents should keep diligent, thrifty and reasonable consumption customs with expenditure according to revenue, resist impulse shopping and luxury consumption to establish the rational consumption concept for children, timely and reasonably guide the consumption conditions of children; fourthly, insist on the green life style such as refusing using or using as little as possible the disposable articles, advocating walking and trying to take public transport means etc to promote children to gradually get used to the low carbon, environmental and healthy life style.

The second is that the construction of ecological personality of citizens runs through the whole process and whole aspects of school education. The psychologists think that most of the cultivation of individual behavioral habits is before 12. The influence of education on individual is diminishing with growth of age, therefore the cultivation of ecological personality of citizens should begin from childhood and the schools play leading roles on cultivation of ecological personality of citizens. The first is to form campus ecology atmosphere which should adopt the green concept and combine with reality of school to promote the popularization of green campus and construct green campus. Use the campus, publicity boards and other places to give publicity to green culture. The university can also rely on school website, class groups, association groups and other new carriers to impart ecological knowledge to students and form campus ecological atmosphere. The second is to bring ecological education into classes. The first is to compile suitable textbooks for ecological personality education according to the student features in different age stages combining with local reality. 
The second is to explore knowledge point of ecological civilization in the courses during the teaching process of other courses and connect with the ecological issues currently concerned by the public (such as the event in which dead pigs floated on the Huangpu River because the mishandling of dead bodies of beasts and birds is an important origin of environmental pollution and epidemic diseases) to enhance the impartation of ecological knowledge, cultivation of ecological morality and development of ecological responsibilities etc to students with pertinence and cultivate the ecological personality of citizens. The third is to organize students to participate in ecological practice. The school should advocate and supervise students to insist on green consumption, save resources and protect environment; encourage students to participate in debate competitions, art competitions, knowledge contests, essay contests and other school activities of ecological culture, organize students to broadly participate in the eco-environment protection experiencing activities such as campus greening, friends of nature, green earth, green river and other Non-governmental Organizations for environmental protection so as to motivate the feelings of appreciation and awe towards nature of students in practice.

Thirdly, give full play to the function of community to cultivate ecological personality of citizens. The community is the main cultural carrier for citizens to carry forward ecological culture and is the main platform to disseminate green development concept, therefore the function of community public life in cultivation of ecological personality of citizens shall be given full play. On one hand, the community can rely on community WeChat public platform, community broadcast, publicity boards and other medium and give full play to the commemoration days such as "World Environment Day", "Earth Day" and "Tree-planting Day" etc to launch various kinds of theme ecological activities and broadly disseminate and popularize knowledge on ecological environmental protection; on the other hand, the community environment shall set out with green development concept, base on the principles of saving, environment protection and beauty, focus on environment greening of community, well manage the environmental health of community, clear the classifying labels for sanitary garbage on garbage cans, set the recycling bins for duds and set recycling boxes for waste battery etc and try to establish the comprehensively harmony and dynamic new ecological order and guide the citizens to internalize their ecological consciousness into ecological behaviors as the ecological man in the true sense.

4) Construct the social environment advocating green development concept with multiple measures: The construction of social environment advocating green development concept must enhance the comprehensive publicity of ecological civilization knowledge, ecological civilization idea and green life style and strengthen the public opinion atmosphere and favorable environment for ecological personality education of citizens.

Firstly, construct the favorable atmosphere for green development. The first is to combine the advantages of high coverage and strong public trust of traditional media and the advantages of openness, sharing and various forms of new media to immerse the citizens in the atmosphere of green development education unconsciously so as to improve the cognition of green development concept. On one hand, use the traditional media to intensify publicity of ecological civilization value. The traditional media can conduct publicity and education of ecological civilization through broadcasting station, Television Station broadcasting current affairs and news on ecological, putting up pictorial magazines of environmental protection and green life on community publicity boards and other traditional measures. On the other hand, enhance the promotion of green development concept by new media. Using various network techniques and new media, through measures such as establishment of WeChat public platform for green development, news client, timely updating the discussion topics about ecological civilization on the Microblog, conduct effective real-time interaction with citizens. The second is to complete the performance assessment system, take green development as a main index for local government examination, launch ecological protection competition activities in towns and communities, commend and reward the relevant units and individuals to motivate the public to protect ecological environment, promote the positivity and initiative and cultivate the favorable atmosphere for construction of ecological personality of citizens. The third is to advocate green life style in the whole society. Use strength from various aspects including the government, law and public opinion in the whole society to vigorously advocate citizens to practice green life style including green traveling and green consumption etc. Life should take green and health as targets while the consumption should adopt saving and environmental protection as principles so that the ecological consciousness of citizens can be transferred into ecological habits and behaviors.

Secondly, construct the green and ecological natural environment. The green and ecological social environment is the important ground for "environment education" of citizens. The government can optimize the natural environment of community; establish the beautiful community with distinct features, reasonable layout and favorable ecology through expanding green areas, improving green quality, keeping the consistency of green plants seasons and other measures so as to let citizens feel the values of environment and change the attitude toward environment in natural environment of favorable community and further realize the objectives of "education about environment", "education for environment" and "education in environment".

Thirdly, complete various facilities and equipment for ecological environmental protection of the society. The green development concept must be solidly constructed on details. The government can make environmental protection facilities be seen everywhere and be used at any time through a series of measures including optimizing urban bus routes and repairing dedicated parking places for bicycles etc and let citizens gradually cultivate green life style through the detailed hints. Citizens can effectively learn ecological civilization ideas, know ecological civilization ideas, experience green life style and can continuously deepen the acknowledgement of green development concept as well as complete their ecological personality in the social atmosphere advocating green development concept. 


\section{CONCLUSION}

In conclusion, green development is the important measure to achieve the goal of building a moderately prosperous society in all respects. The ecological personality of citizens is the main personality demand for realization of green development. The internal combination of ecological personality construction and green development is determined by the realization of ecological personality of citizens and sustainable development. Only when we improve and implement the legal system for green development of our country, strengthen the ecological governance position of the ecological serviceorientated government, complete the integrated construction of ecological personality training of citizens, build the social environment advocating green development concept, complete the construction of ecological personality of citizens, can we promote the national ecological civilization construction and realize the beautiful Chinese Dream.

\section{REFERENCES}

[1] People's Publishing House. Decision of the Central Committee of the Communist Party of China on Some Major Issues Concerning Comprehensively Deepening the Reform (offprint of the important decisions of the Third Plenary Session of the 18th CPC Central Committee) [M]. People's Publishing House, 2013

[2] Propaganda Department of CPC Central Committee. Meeting Correspondence of the Series of Important Addresses of the General Secretary Xi Jinping (edition 2016) [M]. Xuexi Publishing House, 2016. 